\title{
Correction to: Using multilocus sequence analysis to distinguish pathogenic from saprotrophic strains of Pseudomonas from stone fruit and kiwifruit
}

\author{
Sandra B. Visnovsky • Maria V. Marroni • Shamini Pushparajah • Kerry R. Everett • \\ Robert K. Taylor • Boris A. Vinatzer • Andrew R. Pitman
}

Published online: 13 August 2019

(C) Koninklijke Nederlandse Planteziektenkundige Vereniging 2019

\section{Correction to: European Journal of Plant Pathology https://doi.org/10.1007/s10658-019-01799-8}

This erratum has been created as many author corrections were overlooked in proofing stage.

The online version of the original article can be found at https: https://doi.org/10.1007/s10658-019-01799-8

S. B. Visnovsky $(\bowtie) \cdot$ M. V. Marroni $\cdot$ A. R. Pitman

The New Zealand Institute for Plant and Food Research Ltd, Private Bag 4704, Christchurch 8140, New Zealand

e-mail:sandra.visnovsky@plantandfood.co.nz

S. Pushparajah · K. R. Everett

The New Zealand Institute for Plant and Food Research Ltd, Private Bag 92169, Auckland 1142, New Zealand

URL: http://www.plantandfood.com/

S. B. Visnovsky · R. K. Taylor · A. R. Pitman

Better Border Biosecurity, New Zealand

URL: http://www.b3nz.org

R. K. Taylor

Plant Health and Environment Laboratory, Ministry for Primary Industries, P.O. Box 2095, Auckland 1140, New Zealand

B. A. Vinatzer

School of Plant and Environmental Sciences, Virginia Tech,

Blacksburg, VA 24061, USA 